\title{
ВЗАИМОСВЯЗЬ ФИЗИКО-ХИМИЧЕСКИХ ХАРАКТЕРИСТИК ОРГАНИЧЕСКИХ СОЕДИНЕНИИ С ИХ ТЕРМОДИНАМИЧЕСКИМИ КОЭФФИЦИЕНТАМИ АКТИВНОСТИ В ФЕНОЛАХ
}

L. MOLDER, O. METLITSKAJA, H. TAMVELIUS, ORGAANILISTE OHENDITE FOOSIKALIS. KEEMILISTE PARAMEETRITE SEOS NENDE TERMODONAAMILISTE AKTIIVSUSTEGU. RITEGA FENOOLIDES

L. MOLDER, O. METLITSKAYA, H. TAMVELIUS. RELATIONSHIP BETWEEN PHYSICO-CHEMICAL PARAMETERS OF ORGANIC SOLUTES AND THEIR ACTIVITY COEFFICIENTS IN PHENOLS

\section{(Представил О. Эйзен)}

В ['] нами было показано существование явной взаимосвязи экспериментальных коэффициентов активности $\left(\gamma^{\infty}\right)$ органических соединений в одно- и двухатомных фенолах и их эфирах с характеристиками чистых растворенных соединений. При этом использовали известное полипараметрическое линейное уравнение, предложенное в $\left[{ }^{2}\right]$ для корреляции констант скорости и равновесия химических реакций и включающее в качестве коррелирующих параметров полярность $Y(Y \equiv$ $\equiv(\varepsilon-1) /(2 \varepsilon+1)$, где $\varepsilon-$ диэлектрическая проницаемость), поляризуемость $P\left(P \equiv\left(n^{2}-1\right) /\left(n^{2}+2\right)\right.$, где $n-$ показатель преломления $)$, электрофильность $E$ и нуклеофильность $B$. Это уравнение $\left((5.23)\right.$ в $\left.\left[{ }^{2}\right]\right)$ ранее неоднократно и успешно использовалось также для описания взаимосвязи коэффициентов активности -и распределения с характеристиками чистых органических соединений. Однако полученные при этом коэффициенты регрессии действительны только в том случае, если рассматривают набор растворенных соединений в данном растворителе или данное растворенное вещество в наборе растворителей.

В настоящей работе показывается, что в растворителях одного гомологического ряда (алкилпроизводных фенола) взаимосвязь $\ln \gamma^{\infty}$ с характеристиками чистых растворенных соединений можно удовлетворительно описывать с помощью одного набора коэффициентов регрессии, общего для всех растворителей. Такой подход обоснован относительной близостью коэффициентов регрессии, полученных для зависимости $\ln \gamma^{\infty}$ растворенных соединений в отдельных фенолах.

Действительно, обработка экспериментальных данных $\ln \gamma^{\infty}$ органических соединений (приведены в [']) в 2-пропил-, 4-пропил-, 2-вторбутил, 4-бутил, 4-втор-бутил, 2,4-ди-трет-бутил- и 4-амилфенолах (всего 101 значение $\gamma^{\infty}$ ) показала, что в любом феноле

$$
\ln \gamma_{i}^{\infty}=b_{0}+b_{1} Y+b_{2} P+b_{3} E+b_{4} B+\pi_{i},
$$

где коэффициенты регрессии $b_{0}, b_{1}, \ldots$ являются общими для всех названных фенолов, а член $\pi_{i}$ эмпирически учитывает различия в свойствах растворителей и стандарта, для которого $\pi_{i}=0$.

Приняв в качестве стандарта 4-бутилфенол, получили: $b_{0}=$ $=1,914 \pm 0,597, b_{1}=0,302 \pm 0,574, b_{2}=-2,704 \pm 2,224, b_{3}=-0,0582 \pm 0,0152$, $b_{4}=-0,0141 \pm 0,0007$ (коэффициент корреляции $r=0,951$, стандартное отклонение величин $\left.\ln \gamma_{i}^{\infty} s_{i}=0,490, s, \%=9,80^{*}\right)$.

* $s, \%=100 s / \Delta \ln \gamma_{i}^{\infty}$, где $\Delta \ln \gamma_{i}^{\infty}-$ диапазон изменения $\ln \gamma_{i}^{\infty}$. 
Поскольку стандартные отклонения коэффициентов регрессии $\left(s_{b}\right)$ $b_{1}$ и $b_{2}$ по сравнению с отклонениями величин самих коэффициентов высоки (т. е. коэффициенты регрессии $b_{1}$ и $b_{2}$ мало достоверны), были проведены аналогичные расчеты с исключением одного или обоих входных параметров $Y$ и $P$. Результаты расчетов показали, что хотя $\ln \gamma_{i}^{\infty} \quad$ в принципе должен зависеть от всех четырех параметров ( $Y$ и

$P$ учитывают различие неспецифических сил между одинаковыми и различными молекулами в растворе), в рассматриваемых системах влияние $Y$ и $P$ на избыточную энергию Гиббса является несущественным, и

$$
\ln \gamma_{i}^{\infty}=b_{0}+b_{3} E+b_{4} B+\pi_{i},
$$

где $b_{0}=1,283 \pm 0,131, b_{3}=-0,0552 \pm 0,0141, b_{4}=0,0136 \pm 0,0005 \quad(r=0,950$, $s=0,489, s, \%=9,78$ ).

Величины $\pi_{i}, r_{i}$ и $s_{i}$, полученные по обоим вариантам регрессионного уравнения для отдельных фенолов, представлены в таблице.

Включение данных о $\ln \gamma_{i}^{\infty}$ в двух алкоксипроизводных фенола (гваяколе, 2,6-диметоксифеноле) значительно ухудшает корреляцию, что, несомненно, указывает на ограниченность применения изложенного подхода и на необходимость более дифференцированного учета свойств растворителей, чем в настоящем сообщении. Тем не менее включение дополнительных параметров на основании имеющегося относительно небольшого экспериментального материала явно не оправдано.

Авторы считают, что полученные коэффициећты регрессии уравнений (1) и (2) могут быть использованы для приблизительной оценки $\gamma^{\infty}$ неэлектролитов в алкилфенолах, если в данном феноле имеется хотя бы одно достоверное значение $\gamma^{\infty}$.

$\pi_{i}, \boldsymbol{r}_{i}$ и $\boldsymbol{s}_{i}$ для отдельных фенолов

\begin{tabular}{l|c|c|c|c|c|c}
\hline \multirow{2}{*}{ Фенол } & \multicolumn{3}{|c|}{ Уравнение (1) } & \multicolumn{3}{|c}{ Уравнение (2) } \\
\cline { 2 - 5 } \cline { 5 - 7 } & $100 \pi_{i}$ & $r_{i}$ & $s_{i}$ & $100 \pi_{i}$ & $r_{i}$ & $s_{i}$ \\
\hline & & & & & & \\
2-Пропилфенол * & $-3,67$ & 0,956 & 0,411 & $-1,11$ & 0,944 & 0,392 \\
4-Пропилфенол * & 7,20 & 0,958 & 0,423 & 9,77 & 0,948 & 0,400 \\
2-втор-Бутилфенол & $-7,08$ & 0,959 & 0,580 & $-6,59$ & 0,959 & 0,534 \\
4-Бутилфенол & 0,0 & 0,952 & 0,599 & 0,0 & 0,952 & 0,553 \\
4-втор-Бутилфенол & 18,96 & 0,947 & 0,667 & 18,96 & 0,948 & 0,601 \\
2,4-дн-трет-Бутил- & & & & & \\
фенол & $-28,57$ & 0,944 & 0,573 & $-27,81$ & 0,944 & 0,532 \\
4-Амилфенол & $-4,08$ & 0,948 & 0,576 & $-4,08$ & 0,947 & 0,532 \\
\end{tabular}

* $\Delta \ln \gamma^{\infty}$ около 1,$4 ;$ в остальных фенолах около 4,6 .

\section{Л ИТЕ РА Т У РА}

1. Мельдер Л., Метлицкая О. Корреляция предельных коэффициентов активности неэлектролитов с их свойствами. - Изв. АН ЭССР. Хим., 1985, 34, № 3 . $196-200$.

2. Koppel, I. A., Palm, V. A. The influence of the solvent on organic reactivity. In: Advances in Linear Free Energy Relationships, 5. London, New York, $1972,203-280$.

Ннститут химии

Академии наук Эстонской ССР
Поступила в редакцию $22 /$ II 1985

Таллинский политехнический институт 